\title{
NUMERICAL INVESTIGATIONS IN TO CRASHWORTHINESS CHARACTERISTICS OF STEEL CONICAL TUBES
}

\author{
I. A. Rafukka* \\ Department of Mechanical EngineERing, Bayero University, PMB 3011, KANo, Kano State. NiGERIA \\ E-mail address: ibrahimrafukka@yahoo.com
}

\begin{abstract}
This work investigates the crash response of conical tubes made from different steel grades ranging from low to high strength steels using finite element (FE) simulations. The FE model was first validated against experimental results before being applied for the numerical analysis using LS DYNA software. Peak crushing load, mean load, energy absorption, crush force efficiency (CFE) and specific energy absorption (SEA) were evaluated from the cones of different steel grades and of various thicknesses. It was found that high strength steel exhibit high SEA and low CFE values. Both SEA and CFE were found to increase with increase in tube wall thickness for the five steel compared. For improved safety of the occupant, steel-CA5 is best because of higher CFE values for $1.5 \mathrm{~mm}, 2.0 \mathrm{~mm}$ and $2.5 \mathrm{~mm}$ thicknesses. For better weight reduction, steel-DP600 with SEA of $10.6 \mathrm{~kJ} / \mathrm{kg}$ is the best. Steel-HA3 and steel-SAP $H 440$ with $2.5 \mathrm{~mm}$ thickness offer moderate CFE and SEA values. The findings of this study are useful in designing high safety performance vehicle front energy absorption components.
\end{abstract}

Keywords: Conical tube; Crashworthiness; Crush force efficiency; Specific energy absorption

\section{INTRODUCTION}

Automotive accident has become a major public health problem worldwide. Vehicles are currently produced with high energy absorption thin wall frontal structures that dissipate kinetic energy during automotive crash there by transmitting lower deceleration to the vehicle and hence protecting the occupants [1]. Energy absorption of thin wall components is very vital as it improves crashworthiness of vehicle by absorbing impact energy through plastic deformation and fracture with little increase in body weight. Finite element simulations have been applied by many researchers in the design and optimization of energy absorption structures of various geometries and thickness because physical testing is costly. Steel thin wall tubes specifically with conical shape have been one of the most efficient energy absorbers as they crush in a stable and progressive manner [2]. Conical tubes have advantage over circular and square section tubes because they have minimum chances of deforming by global bending mode.

Investigation of energy absorption of thin wall structures had been reported by many researchers [14]. FE analysis has been applied in studying crashworthiness of various steel section including square, circular, frusta and hybrid structures made from metal and composites with the aim of obtaining high energy and light weight structural components [5]-[11]. Tapered tubes have been recently used as energy absorption components because of their light weight and effective crashworthiness performance. Energy absorption behaviour of empty steel and foam filled conical tubes have been studied [2, 3] . Effect of steel material properties and wall thickness on energy absorption under axial and oblique loading for various column sections, has also been reported [9]. Several other works deal with improving energy absorption of steel conical tube by introducing a trigger or filling with foam $[4,12]$. There is limited research on comparison of crashworthiness characteristics of conical tube made from steel of various levels of strength.

Though steel tubes have setback in their weight compared to their non-metallic counterpart, they are still being used as energy absorbers in automobiles applications because they are cheap and have high strength and stiffness. Research works on crash performance of steel tubes of various cross sections were based on a single steel grade. The objective of this study is to investigate and compare the energy absorption and crush behaviour of conical tubes of different steel grades and wall thicknesses.

*Author, tel: $+234-803-874-9657$ 


\section{METHOD OF INVESTIGATION}

This section provides definition of crashworthiness parameters for axially loaded conical tubes, methods of finite element modelling of the cone and impactor, model validation and results and discussions.

\subsection{Crashworthiness parameters}

Energy absorption performance of thin wall tubes is evaluated using load-displacement response. Loaddisplacement curve also allows for the determination of peak load and mean load. Energy absorption $E_{a}$ as seen in Equation (1) is computed by integrating the load displacement curve:

$$
E_{a}=\int_{0}^{\delta_{\max }} P \delta d \delta
$$

Where $\mathrm{P}$ is the instantaneous crushing load, $\delta$ and $\delta_{\max }$ are the current and maximum attainable deformations. Energy absorbed per unit weight (m) known as specific energy absorption (SEA) is particularly important when weight reduction of structure is required. It is defined in Equation (2) as:

$$
S E A=\frac{E_{a}}{m}
$$

Peak initial load $\left(P_{\max }\right)$ also known as crush force in the load displacement response determines the deceleration transmitted to the vehicle occupant in crash event. $P_{\max }$ is the highest initial load point in the load displacement curve as shown in Figure 1. It indicates the load needed to initiate collapse. It is therefore need to be minimized.

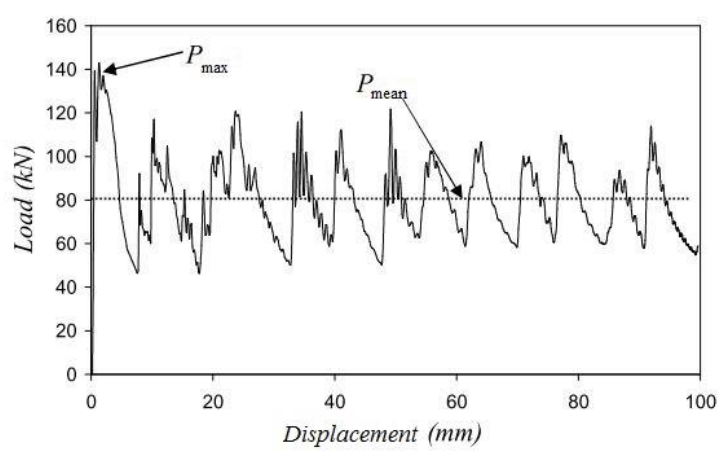

Figure 1: Typical load-displacement response of metallic foam filled circular tube [2]

The mean load, $P_{\text {mean }}$ is also related to energy absorption as given in Equation (3):

$$
P_{\text {mean }}=\frac{E_{a}}{\delta}
$$

Crush force efficiency (CFE) defines the uniformity of crush loads. It is desired to be high for an energy absorber. It is expressed in Equation (4) as:

$$
C F E=\frac{P_{\text {mean }}}{P_{\text {max }}} \times 100
$$

\subsection{Finite element model development}

To verify that the conical tube FE model represent physical tube under crash condition, deformation modes of FE model is compared with existing experimental results [3]. The conical tube of $5^{\circ}$ semiapical angle, $150 \mathrm{~mm}$ length and $54.1 \mathrm{~mm}$ and $79.9 \mathrm{~mm}$ top and bottom diameter as well as $1.14 \mathrm{~mm}$ wall thickness was hit by rigid plate at a prescribed velocity of $2 \mathrm{~m} / \mathrm{s}$. The investigation was carried out using explicit finite element code Ls-dyna [13]. The tube was modelled using Belytschko- Tsay shell element with five integration points through its thickness. 8-noded solid element was applied for the impactor. Piecewise linear plasticity (material type 24) was used to model steel material properties of the tube. Stress-strain curve and material parameters were obtained from literature [3]. Convergence study was conducted and the FE model converged at element size of $2.8 \mathrm{~mm}$ because incorrect mesh size results in error in the findings [14]. Contact automatic surface to surface algorithm with 0.3 and 0.2 static and dynamic coefficients were employed between the tube and rigid plate to avoid lateral movement. The bottom end of the tube was constrained from displacement and rotation using Boundary single point constraint option. Contact automatic single surface was used to avoid interpenetration between elements in the model. The impactor was constrained to move along vertical direction only. The simulation was run on Ls-dyna solver with computation time of about 45 minutes. Figure 2 shows the simulation setup.

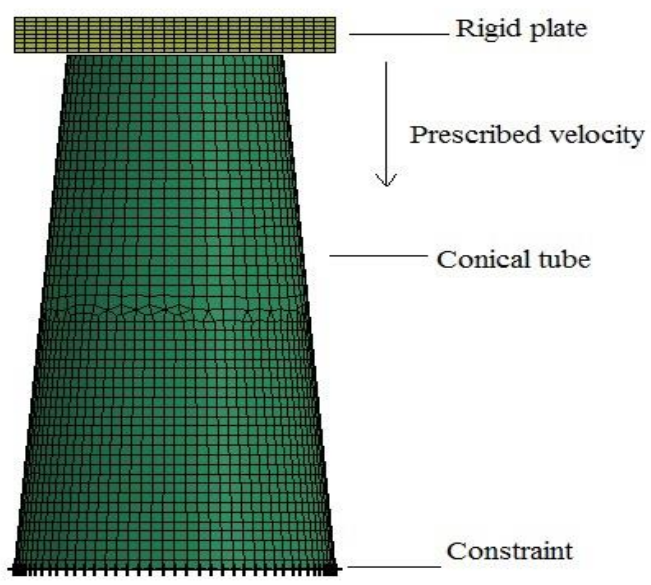

Figure 2: Simulation setup

After the validation, four conical tube FE models were created with the same geometry as the validation model. Stress-strain curve and material properties of steels of various level of strength were obtained from [9] as shown in Table 1. 
Table 1: Mechanical properties of the materials

\begin{tabular}{lcccc}
\hline Material's name & Density $\left(\mathrm{kg} / \mathrm{mm}^{3}\right)$ & Poisson's ratio & Yield stress (MPa) & Ultimate stress (MPa) \\
\hline Steel-CA5 & $7.80 \mathrm{E}-6$ & 0.3 & 130 & 270 \\
Steel-HA3 & $7.80 \mathrm{E}-6$ & 0.3 & 235 & 340 \\
Steel-SAPH440 & $7.80 \mathrm{E}-6$ & 0.3 & 358 & 460 \\
Steel-DP600 & $7.80 \mathrm{E}-6$ & 0.3 & 445 & 673 \\
\hline
\end{tabular}

\subsection{Model Validation}

It is clearly shown in Figure 3 that numerical results from present work agree well with experimental results. The maximum initial crushing force $\left(P_{\max }\right)$ for FE model and experiments are $50.2 \mathrm{kN}$ and $55 \mathrm{kN}$ respectively. Equal number of peaks shown in Figure 3 also confirmed correlation in folding behaviour for the FE model and physical tube.

Figure 4 shows that FE model of conical tube from current study simulates the deformation modes of physical conical tube from experiment [3]. Both tubes folded at the loaded end with axisymmetric mode followed by non-axisymmetric diamond mode.

\subsection{Results and discussions}

Crushing force of the tube is higher for materials of high yield strength as shown in Figure 5. Initial peak load (crush force) for steel-DP600 with yield stress of $445 \mathrm{MPa}$ is $59.0 \mathrm{kN}$ where as that of steel-CA5 with yield stress of $130 \mathrm{MPa}$ is $25.5 \mathrm{kN}$. This is indication of the internal energy absorbed by the tube to make it initially deformed. Crushing force needs to be small because it is related to the deceleration of the vehicle during crash. Other peak values of the force represent the progressive folding of the tube wall.

High strength steels needs more energy to make it plastically deformed. Energy absorbed was evaluated by integrating load-displacement curve in Ls-Prepost as indicated in Equation (1). From the steel grades compared, the energy absorbed is in order of the strength as shown in Figure 6. The energy absorption increases with increase in steel's strength.

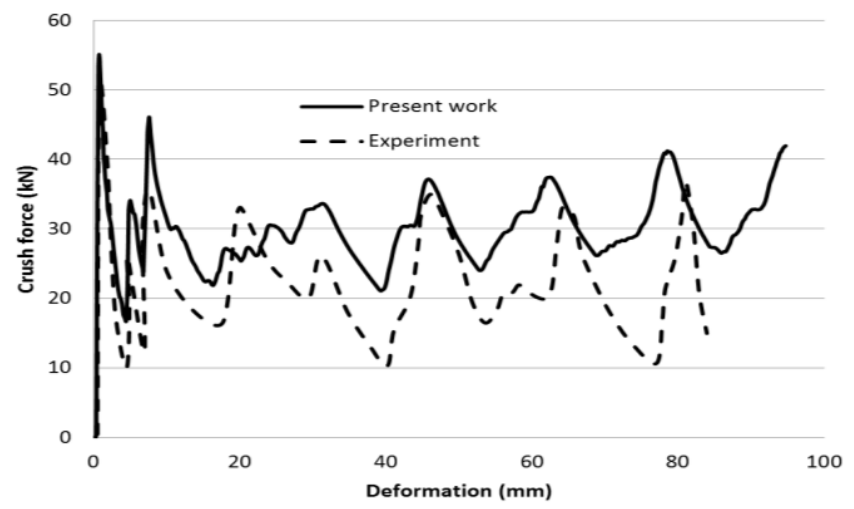

Figure 3: Comparison of load deformation curve of FE model and experimental results [3]

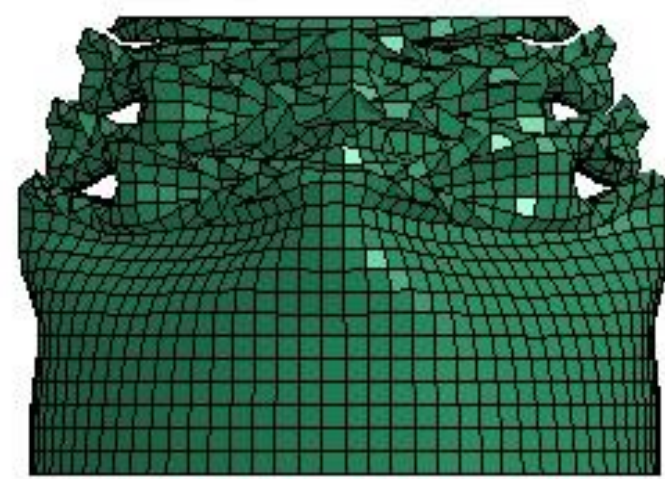

(a)

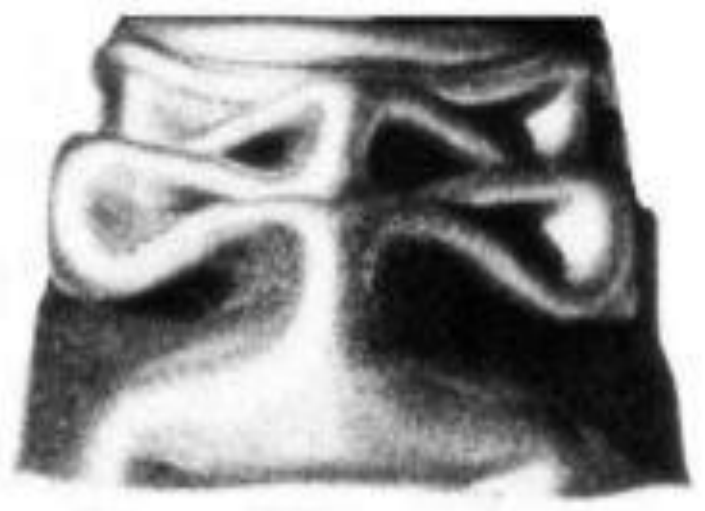

(b)

Figure 4: Collapse mode comparisons between FE model (a) and existing experimental results (b)

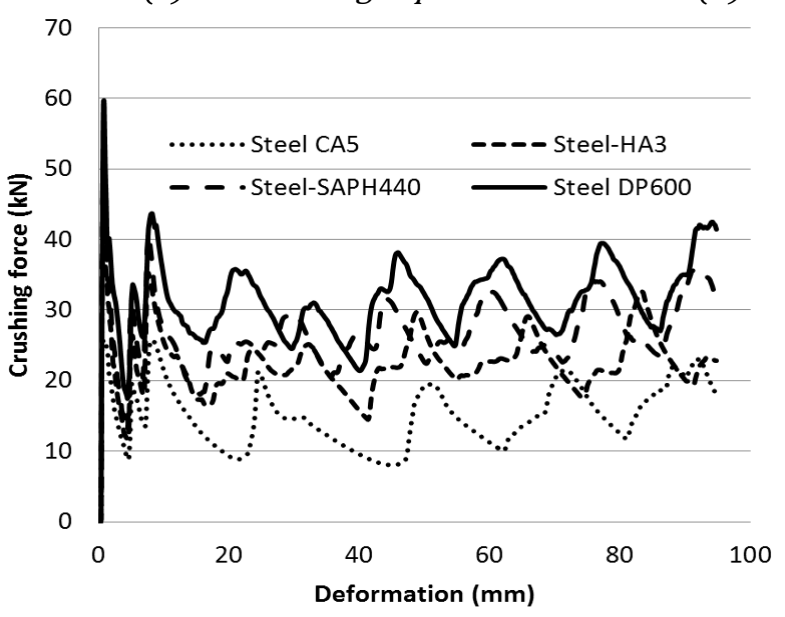

Figure 5: Comparison of crushing force-deformation for various steel grades 
Table 2: Crashworthiness parameters of conical tube

\begin{tabular}{lcccccc}
\hline Steel grade & $\begin{array}{c}\text { Energy absorption, } \\
E_{a}(\mathrm{~kJ})\end{array}$ & $\begin{array}{c}\text { Weight, } \\
(\mathrm{kg})\end{array}$ & $\begin{array}{c}\text { Initial peak load, } \\
P_{\max }(\mathrm{kN})\end{array}$ & $\begin{array}{c}\text { Mean load, } \\
P_{\text {mean }},(\mathrm{kN})\end{array}$ & $\begin{array}{c}\text { CFE, } \\
(\%)\end{array}$ & $\begin{array}{c}\text { SEA, } \\
(\mathrm{kJ} / \mathrm{kg})\end{array}$ \\
\hline Steel-CA5 & 1413.4 & 0.28 & 25.5 & 14.9 & 58.4 & 5.0 \\
Steel-HA3 & 2122.6 & 0.28 & 38.3 & 22.4 & 58.5 & 7.6 \\
Steel-SAPH440 & 2528.3 & 0.28 & 51.0 & 26.7 & 52.4 & 9.0 \\
Steel-DP600 & 2979.1 & 0.28 & 59.0 & 31.5 & 53.4 & 10.6 \\
\hline
\end{tabular}

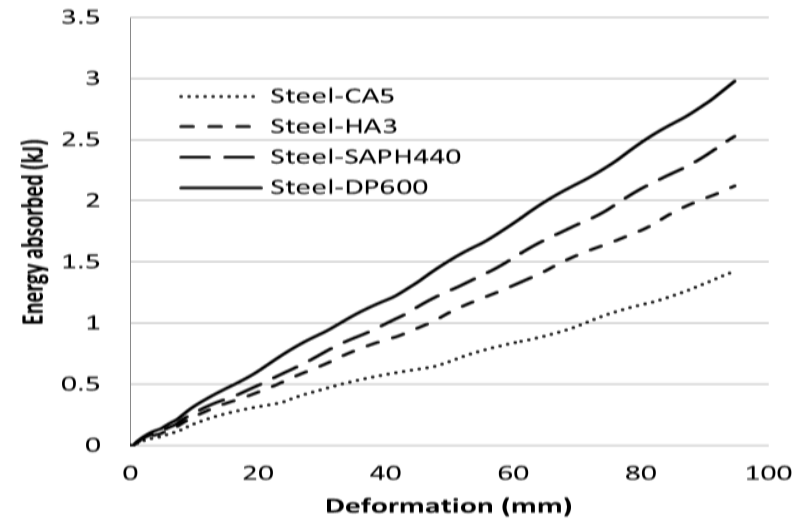

Figure 6: Comparison of energy absorption for various steel grades

SEA is an indicator of energy absorption in terms of the weight of the tube. It is obtained using Equation (2). It is obvious from Table 2 that SEA follows the energy absorption $\left(E_{a}\right)$ of the steel tubes as it increases with increase in steel strength. CFE which is determined using Equation (4), is however high and approximately the same for two low strength steels (Steel-CA5 and Steel-HA3). But high strength steels (Steel-SAPH440 and Steel-DP600) showed low CFE values. This is as a result of higher initial peak force experienced by the tubes of high strength steels. High initial peak load means high load will be transferred to the vehicle components and occupants.

\subsection{Effect of thickness on crashworthiness parameters} The effect of thickness of the tube on SEA and CFE is evaluated. Figure 7 provides clear comparison of SEA values for various thickness and materials type. SEA increases with increase in section thickness because of more material volume to undergo deformation. For each shell thickness considered, the low carbon steel exhibits lower SEA while high strength steels have the high SEA values. This is because the steel with high yield strength absorbs high internal energy to make it deform. Even though tubes with thicker section are heavier compared with thinner ones, high energy absorbed by high strength steels is responsible for its high SEA.

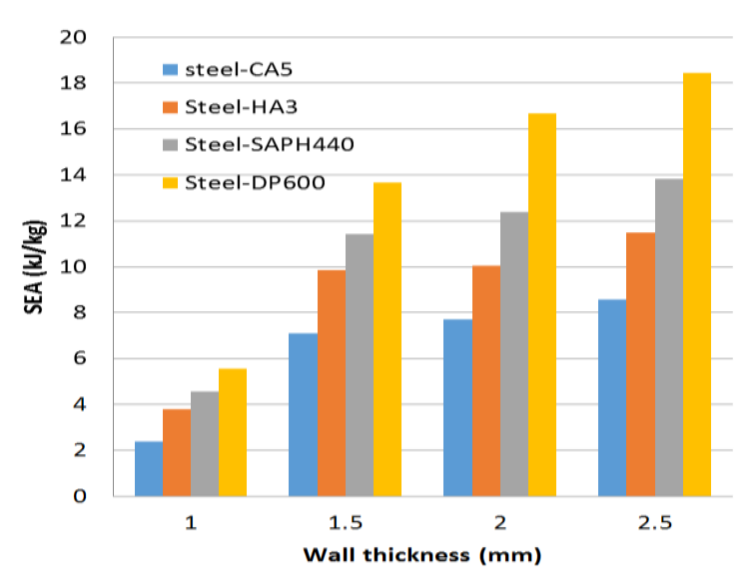

Figure 7: Effect of tube thickness on SEA for various steel types

CFE is a significant comparator of crush effectiveness of an absorber. It is required to be as close to $100 \%$ as possible for an ideal crush absorber. Figure 8 shows clearly the CFE of different steel types with respect to wall thickness. Low strength steels show higher CFE values than high strength steels. Like the SEA, the CFE also increase as the thickness increases. This is attributable to energy absorption experienced by thicker sections because of their stiffness, which results in higher mean load and CFE. Increase in both SEA and CFE with wall thickness has been observed in the previous work [9] for octagonal, hexagonal, rectangle and 12 edge steel columns. For $1 \mathrm{~mm}$ and $1.5 \mathrm{~mm}$ wall thickness, the CFE decrease with material strength. The same trend could be seen for $2 \mathrm{~mm}$ and $2.5 \mathrm{~mm}$ with exception of Steel-DP600 which exhibit strength higher than that of Steel-SAPH440.

For all the cases studied, thicker section tubes possessed highest SEA and CFE values. A compromise has to be made in selecting a design that yields optimum SEA and CFE values. In the present study a good candidate design could be obtained for $2.5 \mathrm{~mm}$ thickness. If safety of the occupant is a priority steelCA5 for $1.5,2.0$ and $2.5 \mathrm{~mm}$ thickness is best in transmitting lower deceleration to vehicle occupants because of higher CFE values. If weight reduction is needed then steel-DP600 with the highest SEA is the best. Steel-HA3 and steel-SAP H440 with $2.5 \mathrm{~mm}$ thickness offer moderate CFE and SEA values. 


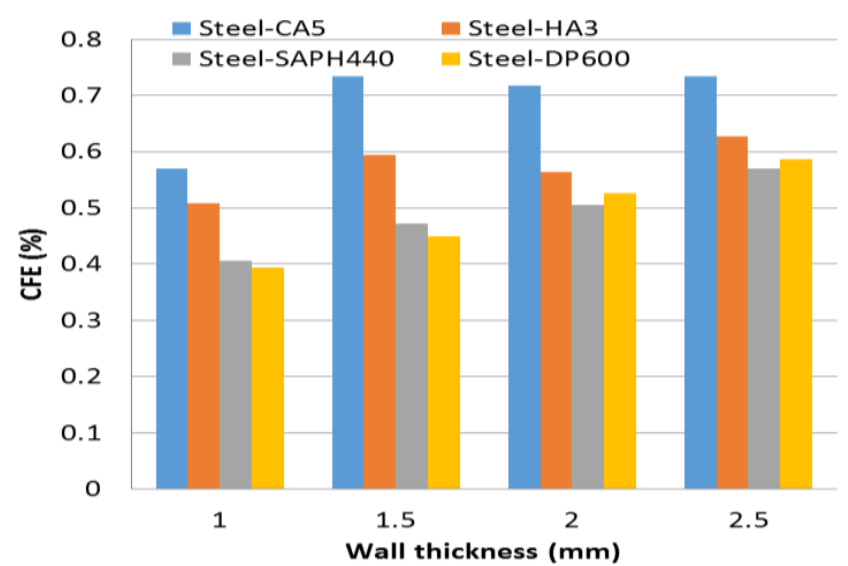

Figure 8: Effect of tube thickness on CFE for various steel types

\section{CONCLUSION}

This study's findings provide information regarding steels that could be used to improve crashworthiness performance of automotive body structures. A well validated FE model could be used to study crashworthiness performance of structures without necessarily using experimental tests which is costly and consumes time. The analysis shows that high strength steel exhibit high energy absorption. But low strength steel offers better crush force efficiency for all thickness. SEA and CFE values increase with increase in thickness. It will be interesting to determine optimum design of conical tube in terms of wall thickness, length and semi-apical angle that provides better crashworthiness parameters. Full vehicle crash test simulation using crash dummy FE model could also be conducted to determine the safe speed limit using the high energy absorption steel conical tube as the crash box of the vehicle.

\section{REFERENCES}

[1] H. Han, F. Taheri, and N. Pegg, "Quasi-Static and Dynamic Crushing Behaviour of Aluminium and Steel Tubes with a Cutout," Thin-Walled Struct, vol. 45, pp. 529-551, 2007.

[2] Z. Ahmad, "Impact and Energy Absorption of Empty and Foam-filled Conical Tubes," Queensland University of Technology, 2009.

[3] A. G. Mamalis, D. E. Manolakos, N. B. Ioannidis, and P. K. Kostazos, "Numerical simulation of thinwalled metallic circular frusta subjected to axial loading.," Int. J. Crashworthiness, vol. 10, no. 5, pp. 505-513, 2005.
[4] F. Mat, K. A. Ismail, M. Ahmad, and M. R. M. Rejab, "Foam Filling Effectiveness of Conical Aluminium Tubes Under Dynamic Axial and Oblique Loading," ARPN J. Eng. Appl. Sci., vol. 11, no. 12, pp. 77417747, 2016.

[5] J. Marzbanrad, A. Abdollahpoor, and B. Mashadi, "Effects of the triggering of circular aluminum tubes on crashworthiness," Int. J. Crashworthiness, vol. 14, no. 6, pp. 591-599, 2009.

[6] J. Marzbanrad, M. Mehdikhanlo, and A. S. Pour, "An energy absorption comparison of square, circular , and elliptic steel and aluminum tubes under impact loading," Turkish J. Eng. Env. Sci, vol. 33, pp. 159-166, 2009.

[7] H. S. Türkmen, Z. Mecito, N. Uluda, and E. Õ. Alt, “A numerical and experimental study on the impact behavior of box structures," Procedia Eng., vol. 10, pp. 1736-1741, 2011.

[8] S. Salwani, B. Sahari, A. Ali, and A. Nuraini, "Optimization of Partially Filled Column Subjected to Oblique Loading," World Acad. Sci. Eng. Technol., vol. 6, pp. 1056-1060, 2012.

[9] M. Abbasi, S. Reddy, A. Ghafari-Nazari, and M. Fard, "Multiobjective crashworthiness optimization of multi-cornered thin-walled sheet metal members," Thin-Walled Struct., vol. 89, pp. 31-41, 2015.

[10] A. C. Moch, P. Anindito, E. Siswanto, and A. H. Nafisah, "Crash Energy Absorbtion of MultiSegments Crash Box Under Frontal Load," J. Teknol., vol. 5, pp. 347-350, 2016.

[11] S. Alkhatib, J. Falsafi, and E. Demirci, "Numerical modelling of steel tubes under oblique crushing forces Numerical modelling of steel tubes under oblique crushing forces," in International Research and Innovation Summit, 2017.

[12] M. J. Rezvani, "Experimental and Numerical Simulation Investigation on Crushing Response of Foam-Filled Conical Tubes Stiffened with Annular Rings," J. Solid Mech., vol. 9, no. 2, pp. 291-301, 2017.

[13] J. 0. Hallquist, Theory manual, no. March. Livermore Software Technology Corporation, 2006.

[14] M. Ahmad, K. A. Ismail, and F. Mat, "Convergence of finite element model for crushing of a conical thin-walled tube," Procedia Eng., vol. 53, pp. 586593, 2013. 